
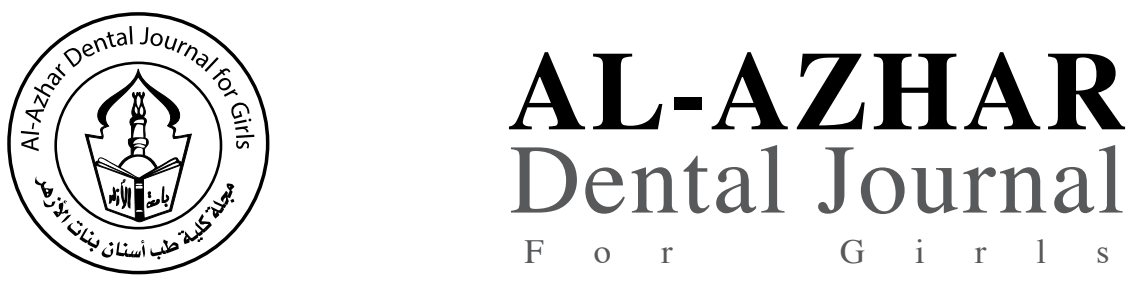

The Official Publication of The Faculty of Dental Medicine For Girls, Al-Azhar University Cairo, Egypt.

ADJ-for Grils, Vol. 3, No. 4, October (2016) — PP. 277:286

\title{
Effect of Primer Type and Ultrasonic Cleaning on Bonding to Zirconia Ceramic
}

\author{
Huda El Rashedy ${ }^{(1)}$, Osama Abd Elgany ${ }^{(2)}$ and Sahar Abd El Wahab ${ }^{(2)}$
}

Codex : 04/1610

dentaljournal.forgirls@yahoo.com

\begin{abstract}
Zirconia-based ceramics offer strong restorations in dentistry, but the adhesive bond strength of resin cements to such ceramics is not optimal. The aim of the present study was to evaluate the effect of both primer types and ultrasonic cleaning on bonding to zirconia ceramics.A total number of forty zirconia discs were constructed from prefabricated blanks of zirconia. The discs were mounted on acrylic blocks and randomly divided into two equal main groups $(n=20)$ According to ultrasonic cleaning. Without ultrasonic cleaning and with ultrasonic cleaning. Every group was subdivided into three subgroups according to type of primer $(n=10)$ Monobond $S$ primer and Monobond Plus primer Forty composite resin blocks were cemented to zirconia discs by (Variolink II) with its corresponding adhesive components. Shear bond strength of each sample was measured using a universal testing machine at a crosshead speed of 1 $\mathrm{mm} / \mathrm{min}$. Shear bond strengths were analyzed through Two-way ANOVA/Tukey tests Treated zirconia ceramic surfaces were examined using scanning electron microscopy. Data was collected and statistically analyzed. Monobond Plus group recorded higher shear bond strength than Monobond S group. Monobond Plus primer improved bonding to zirconia ceramic while the cleaning method had little or no effect.
\end{abstract}

\section{INTRODUCTION}

For the past forty years the porcelain-fused-to-metal systems have been extensively used in fixed partial dentures (FPDs) and still represent the gold standard ${ }^{(1)}$. The advantages of the porcelain fused to metal (PFM) systems is to combine the fracture resistance of the metal substructure with the esthetic property of the porcelain.

However, recently the increasing demand for esthetic restorations as well as the questionable biocompatibility of some dental metal alloys

1. Dentist at Badr hospital, Tanta University.

2. Assistant Professor of Fixed Prosthodontics, Faculty of Dental Medicine, Al Azhar University, Cairo, Egypt. 
has accelerated the development and improvement of metal-free restorations. ${ }^{(2)}$

All-ceramic restorations are favorable alternatives to metal-ceramic and all-metal restorations. All-ceramic restorations have superior esthetics, biocompatibility and durability. There are two major categories of all-ceramic materials: silica-based (feldspathic porcelains, leucite-reinforced ceramics, lithium disilicate ceramics) and non-silica-based (zirconia or alumina).

The luting of a zirconia restoration can be done with zinc phosphate or modified glass ionomer cements. However, the advantages of resin luting agents such as marginal seal, good adhesion and improvement of fracture resistance, have made them more and more frequently used even for high strength ceramics ${ }^{(3)}$.

A large number of resin luting agents, silanes and examples of various surface treatments for all ceramic restorations, have been recommended for these high strength ceramics during recent years. However, specific recommendations for zirconia are more difficult to get and there are obvious problems in obtaining a safe bond between the resin agent and this type of high strength ceramic. Some resin agents have revealed better bonding capacity than others, which may depend up on their wetting capacity.

Etching with hydrofluoric acid is recommended only for surfaces with a glass component, but it has no influence on zirconia ceramics where no microgrooves will be created. For these materials airborne- particle abrasion is an alternative to roughen the surface. Silane is recommended for silica based porcelains in order to form a siloxane network with the silica in the ceramic surface, to improve the bond strength between the ceramic and the luting material. This chemical reaction is not possible for zirconia-based ceramics. It has also been suggested that silanization may improve the wetting ability of the surface and thereby result in small but increased bond strength values.

A newly developed universal primer (Monobond Plus) is claimed by its manufacturer to bond effectively to zirconia ceramic. Moreover after surface conditioning and prior to primer application the bonding surfaces are cleaned from dust resulting from air-borne particle abrasion either by cleaning with a stream of oil-free air or by ultrasonic cleaning.

The first null hypothesis of the study was that application of a new universal primer would not increase bond strength to zirconia ceramic. The second null hypothesis was that ultrasonic cleaning after surface treatment has no effect on bond strength between zirconia ceramic and resin cement.The objective of this study, therefore, was to evaluate the effect of both primer types and ultrasonic cleaning on bonding to zirconia ceramics.

\section{MATERIALS AND METHODS}

Table (1) Materials, Composition, Manufacturers:

\begin{tabular}{|c|l|c|}
\hline Materials & \multicolumn{1}{|c|}{ Composition } & Manufacturer \\
\hline Zirconia & $\begin{array}{l}(\mathrm{Y}-\mathrm{TZP}), \text { it composed of } 94 \%\left(\mathrm{ZrO}_{2}\right), \\
5 \%\left(\mathrm{Y}_{2} \mathrm{O}_{3}\right), \text { and }<1 \%\left(\mathrm{Al}_{2} \mathrm{O}_{3}\right)\end{array}$ & Zir -CERAPP Germany \\
\hline Monobond S & Alcohol solution of silane methacrylate & $\begin{array}{c}\text { Ivoclar-Vivadent, Schaan, } \\
\text { Liechtenstein }\end{array}$ \\
\hline Monobond Plus & $\begin{array}{l}\text { Alcohol solution of silane methacrylate, phosphoric acid methacrylate and sul- } \\
\text { phide methacrylate }\end{array}$ & $\begin{array}{l}\text { Ivoclar-Vivadent, Schaan, } \\
\text { Liechtenstein }\end{array}$ \\
\hline Variolink II & $\begin{array}{l}\text { It's a dual-curing composite cement, it composed of base which is 10-14 \% Bis- } \\
\text { GMA, 5-7\% Triethylene glycol dimethacrylate, 5-7\% Urethane dimethacrylate, } \\
\text { initiators, stabilizers and pigments, and catalyst which is < 1 \%Benzoylperoxid. }\end{array}$ & $\begin{array}{l}\text { Ivochtent, Schaan, } \\
\text { Liechtenstein }\end{array}$ \\
\hline
\end{tabular}




\section{1- Samples preparation}

Forty zirconia discs $(6.5 \mathrm{~mm}$ in diameter and 6 $\mathrm{mm}$ thickness) were constructed from prefabricated blanks of zirconia using Manual-aided Design/ Manual-aided Manufacturing (MAD/MAM) system.

\section{a- Preparation of composite resin pattern}

In order to standardize the shape and dimensions of the samples, a specially designed Teflon mold was machine cut. It consists of a split disc shape divided into two equal halves. The central hole of the split disc was $6.5 \mathrm{~mm}$ in diameter and $6 \mathrm{~mm}$ thickness. The two halves of the Teflon mold were assembled with a hollow plastic ring, then composite resin layers were incrementally condensed into the mold to fill up the mold and were light polymerized for 40 seconds at a distance of $1 \mathrm{~mm}$ using a light-polymerizing unit with an output power of $600 \mathrm{~mW} / \mathrm{Cm}^{2}$.

\section{b- Milling of Y-TZP samples}

After complete polymerization, the composite resin pattern was removed and then placed into the pantographic machine. The copying arm of the machine traced the composite pattern while the cutting arm, which had a carbide cutter, milled a selected pre-sintered zirconia block. The final shape is $20 \%$ to $25 \%$ larger to account for shrinkage during the sintering step. Then all zirconia surfaces were sandblasted with $50 \mu \mathrm{m} \mathrm{Al}_{2} \mathrm{O}_{3}$ at 2.5 bar pressure for 15 seconds at a distance of $10 \mathrm{~mm}$.

\section{2- Samples classification}

Samples were divided equally into two groups according to ultrasonic cleaning $(n=20)$, Group (I) without ultrasonic cleaning, Group (II) with ultrasonic cleaning.

Samples of each group were further subdivided into two subgroups $(n=10)$ according to the type of primer used. Sub group (1): treated with Monobond $S$ primer, Sub group(2) : treated with Monobond Plus primer. Four samples was subjected to SEM one from each group. Primer (Monobond $\mathrm{S}$ or Monobod Plus) was applied to the the conditioned samples surface.

\section{3- Ultrasonic Cleaning}

An ultrasonic cleaner is a cleaning device that uses ultrasound (usually from $20-400 \mathrm{kHz}$ ) and an appropriate cleaning solvent to clean delicate items. Ultrasonic cleaning was done by immersing the zirconia discs in distilled water for 5 minutes.

\section{4- Primer Application}

Primer (Monobond S or Monobod Plus) was applied to the samples surface with clean disposable micro brush in one direction (from right to left or revers). The material was allow to react for $60 \mathrm{sec}-$ onds and then dried with oil-free air for 60 second.

\section{5- Samples cementation}

Variolink II resin cement will be applied to zirconia samples using Teflon mold to standardize the size of the applied cement area. An additional upper two parts were added to previous prefabricated Teflon mold. Every two parts combined together to form a circular disc. Within the center of the lower disk there is a circular hole with its internal dimensions $(6.5 \mathrm{~mm}$ diameter, $6 \mathrm{~mm}$ height $)$. The internal dimensions for the hole in the upper disk $(3.6 \mathrm{~mm}$ diameter, $5 \mathrm{~mm}$ height). The lower hole is used for construction of the zirconia disks while the upper one is used for resin cement (variolink II). Each two parts are assembled together using external Teflon holding ring. Each resin disc was bonded to zirconia core specimens under a load of 500 gm using custom-made cementation device. Micro brushes were used to remove excess resin.

\section{6- Placement of samples in acrylic resin block}

Zirconia samples were embedded in the centers of auto polymerizing acrylic resin blocks to be mounted in the jig of the universal testing machine. 
A paralleling device (Milling surveyor) was used to mount each sample and to ensure the centralization and vertical alignment of it to the mold. All samples before shear bond strength were thermocycled for 3000 cycle's shocks altering between $5^{\circ} \mathrm{C}$ and $55^{\circ} \mathrm{C}$ with 30-second dwell times in each water bath using thermostatically water bath.

\section{7- Shear bond strength measurement and statistical analysis}

All samples were individually gripped in specially designed metal jig (metal cylinder with central cavity for specimen housing in such way the zirconia disc was flushed with jig surface exposing the resin cement)

Samples were secured to the lower fixed compartment of testing machine load applied at zirconia-resin interface using a mono-beveled chisel shaped metallic rod attached to the upper movable compartment of testing machine traveling at crosshead speed of $0.5 \mathrm{~mm} / \mathrm{min}$. The load required to debonding was recorded in Newton. Data were calculated and tabulated.

Shear bond strength values were calculated according to the following formula:-

Shear bond strength $(\mathrm{MPa})=$

fracture load $(\mathrm{N})$

Sample surface area $\left(\pi \mathrm{r}^{2}\right)\left(\mathrm{mm}^{2}\right)$

Where $(r)$ is radius of the samples.

Debonded specimen surface were examined by light microscope to determine the nature of their failure .Failure was classified as adhesive if the fracture site was located entirely between the resin/ cement and zirconia surface, mixed if the fracture continued into the resin/cement and cohesive if the fracture occurred exclusively within the resin/cement.

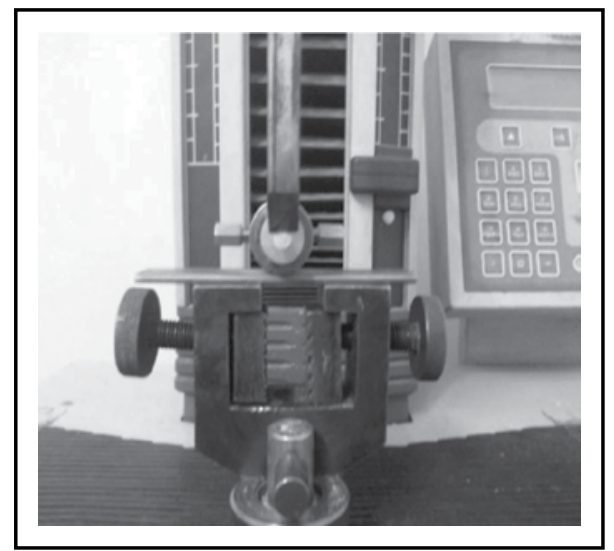

Fig. (1) Test specimen aligned on universal testing machine

\section{RESULTS}

Data analysis was performed in several steps. Initially, descriptive statistics for each subgroup results. Two-way analysis of variance ANOVA tests of significance comparing variables affecting mean values. Student $t$-test was performed to detect significance between paired subgroups. One way ANOVA followed by pair-wise Duncan post-hoc tests were performed to detect significance between groups. Statistical analysis was performed using Assistants 7.6 statistics software for Windows. $\mathrm{P}$ values $\leq 0.05$ are considered to be statistically significant in all tests.

\section{Effect of ultrasonic cleaning on shear bond strength:}

Regardless to primer type, totally it was found that group I recorded statistically non-significant ( $p>0.05)$ lower shear bond strength mean value than group II

Table (2) Comparison of total shear bond strength mean values as function of ultrasonic cleaning

\begin{tabular}{|c|c|c|c|}
\hline \multicolumn{2}{|c|}{ Variable } & Mean $\pm S D$ & Statistics \\
\hline \multirow{2}{*}{$\begin{array}{c}\text { Ultrasonic } \\
\text { cleaning }\end{array}$} & Group I & $17.6 \pm 2.6$ & P value \\
\cline { 2 - 4 } & Group II & $18.4 \pm 2.8$ & $0.8709 \mathrm{~ns}$ \\
\hline
\end{tabular}

$n s$; non-significant $(p>0.05) \quad *$; significant $(p<0.05)$

\footnotetext{
* Model LX-plus; Lloyd Instruments Ltd., Fareham, UK.
} 


\section{Effect of primer on shear bond strength}

Regardless to ultrasonic cleaning, totally it was found that Monobond Plus group recorded statistically significant $(\mathrm{p}<0.05)$ higher shear bond strength mean value than Monobond $\mathrm{S}$ group.

Table (3) Comparison of total shear bond strength mean values as function of primer

\begin{tabular}{|c|c|c|c|}
\hline \multicolumn{2}{|c|}{ Variable } & Mean $\pm S D$ & Statistics \\
\hline \multirow{2}{*}{ Primer } & Monobond S & $11.19 \pm 1.6$ & P value \\
\cline { 2 - 4 } & Monobond Plus & $24.85 \pm 4.5$ & $<0.001^{*}$ \\
\hline
\end{tabular}

*; significant $(p<0.05)$

\section{Group interactions}

It was found that, Monobond Plus without ultrasonic cleaning group recorded the highest mean value followed by Monobond Plus with ultrasonic cleaning group then Monobond $S$ with ultrasonic cleaning group while Monobond $\mathrm{S}$ without ultrasonic cleaning group recorded the lowest mean value.

The difference between groups was statistically significant $(\mathrm{p}<0.05)$ as indicated by ANOVA test. Pair-wise Duncan post-hoc test showed nosignificant $(\mathrm{p}>0.05)$ difference between Monobond Plus with and without ultrasonic cleaning.

Table (4) Group interaction from higher to lower values mean values

\begin{tabular}{|c|c|c|c|c|}
\hline \multicolumn{2}{|c|}{ Variable } & Mean \pm SD & Duncan rank & Statistics \\
\hline Monobond Plus & Without ultrasonic cleaning & $27.60456 \pm 3.885427$ & A & P value \\
\hline Monobond Plus & With ultrasonic cleaning & $22.0788 \pm 5.187271$ & A & \\
\hline Monobond S & With ultrasonic cleaning & $13.38022 \pm 5.18527$ & B & $<0.001^{*}$ \\
\hline Monobond S & Without ultrasonic cleaning & $7.604419 \pm 1.442523$ & $\mathrm{C}$ & \\
\hline
\end{tabular}

Different letters in same column indicating significant irrigation (Duncan $<0.05) \quad *$; significant $(P<0.05)$

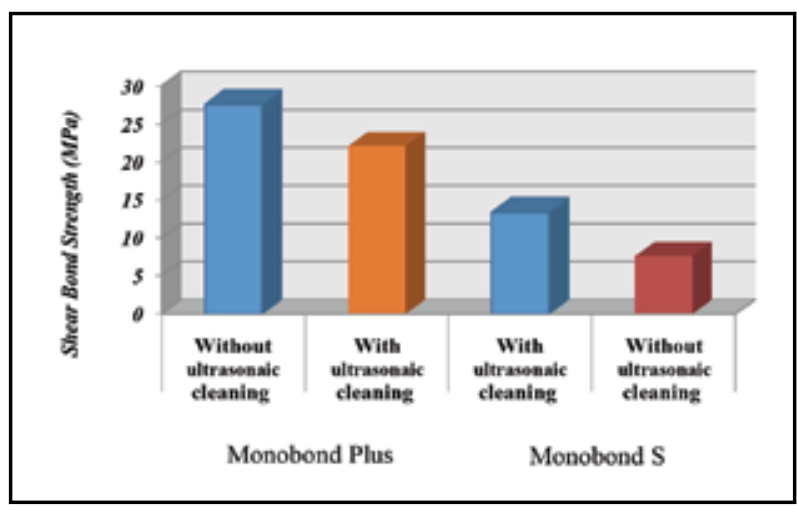

Fig. (2) A column chart of shear bond strength mean values ranked from higher to lower values

\section{Failure mode analysis}

Failure type was noted as adhesive, cohesive or mixed. Failure mode analysis was shown that no recorded samples for cohesive failure in zirconia ceramic. Evaluation of the failure modes after shear testing indicated that high bond strength showed cohesive or mixed modes. As the bond strength decrease the cohesive modes of failure decrease and adhesive mode increase.

In this study the failure modes after shear testing indicated that high bond strength Monobond Plus group without ultrasonic cleaning (IP) showed cohesive or mixed modes followed by Monobond Plus group with ultrasonic cleaning (IIP), then Monobond $\mathrm{S}$ group with ultrasonic cleaning (IIS),While low bond strength Monobond S group without ultrasonic cleaning (IS) tend to exhibit adhesive mode . 
Table (5) Percentage of failure mode after shear testing

\begin{tabular}{|c|c|c|c|}
\hline Failure mode & Adhesive & Cohesive(within resin cement) & Mixed \\
\hline IP & $20 \%$ & $60 \%$ & $20 \%$ \\
\hline IIP & $20 \%$ & $40 \%$ & $40 \%$ \\
\hline IIS & $40 \%$ & $20 \%$ & $40 \%$ \\
\hline IS & $80 \%$ & $0 \%$ & $20 \%$ \\
\hline
\end{tabular}

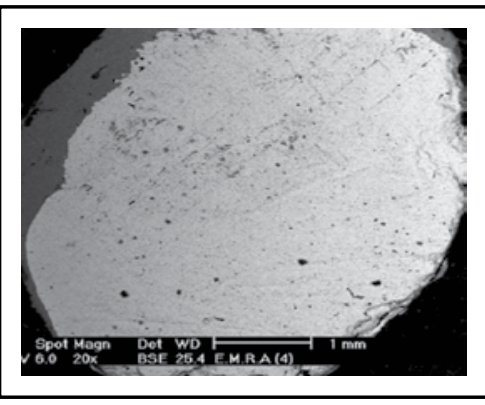

Fig. (3) Representative SEM micrograph (magnification $\times 20$ ) showing adhesive failure at adhesive luting resin/ zirconia ceramic interface

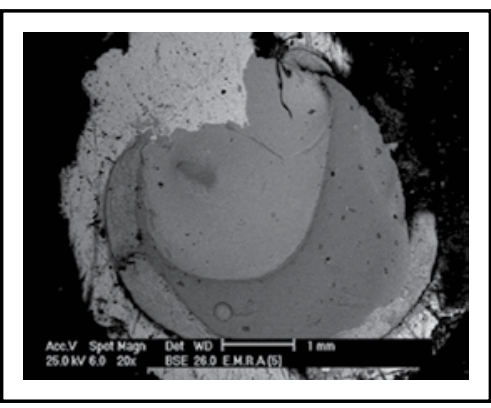

Fig. (4) Representative SEM micrograph (magnification $\times 20$ ) showing a cohesive failure within the adhesive luting resin

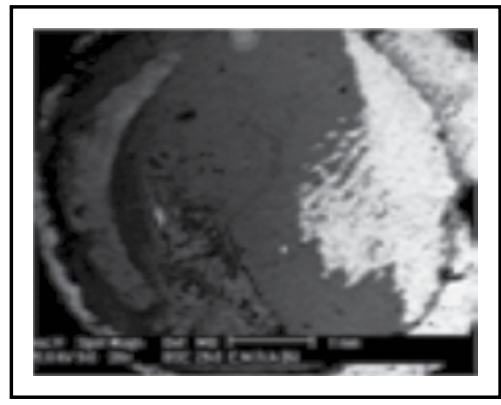

Fig. (5) Representative SEM micrograph (magnification $\times 20$ ) showing mixed failure pattern, cohesive within adhesive luting resin and adhesive at ceramic/luting resin interface.

\section{DISCUSSION}

There has been a significant growth of interest for zirconium oxide(zirconia) ceramics in recent times, with a major impact in the field of prosthodontics and implant dentistry. Due to its mechanical properties biocompatibility, and optical properties, zirconia has been elected as a metal-free alternative. "Transformation toughening" is a distinctive capability of Yttrium stabilized tetragonal zirconia polycrystals (Y-TZP), through which it can resist crack propagation by transforming from a tetragonal to monoclinic phase. One of the major limitations regarding the use of zirconia is the difficulty to adhere to this material. Zirconia FDPs and fullveneer crowns have been successfully used when cemented with conventional cements, such as glass ionomer

The main challenge resides in the fact that highly crystalline ceramics resist conventional etching techniques (absence of a glassy phase) ${ }^{(4)}$. Classic surface roughening methods (airborne-particle abrasion) can only produce a mild coarsening of the zirconia surface ${ }^{(4)}$ and reliable resin bond strength may not be always achieved ${ }^{(5)}$. As a result, a large body of literature has been produced and innovative adhesive strategies combining new surface roughening procedures, laser treatments, and chemical bonding have been developed. Chemical bonding to zirconia ceramics involves the use of various couplers.

The use of a silane coupling agent in combination with aluminum oxide sandblasting presents low bond strength ${ }^{(4,5)}$, which is expected given the absence of silica in the substrate. On the other hand, tribochemical silica coating allows high-strength alumina based and zirconia-based ceramics to be chemically more reactive to resin through silane coupling agents yielding increased resin bond strength values. When this happens, it is highly recommended that the treated surface be cleaned. 
However, cleaning a treated surface may cause the bond strength between the luting material and restoration to decrease ${ }^{(6,7)}$.

This study evaluated the effect of both primer types and ultrasonic cleaning on bonding between resin cement and zirconia ceramics. In accordance with the results, the second null-hypothesis was rejected (effect of ultrasonic cleaning) since the resin-zirconia bond strength was significantly affected by the application of the new primer.

The original roughness produced by the milling during fabrication

is not sufficient to promote adhesion and it seems important to mention that not only cleaning, but roughening and activating the surface are important to achieve durable resin bond to densely sintered zirconia ceramic ${ }^{(8,9)} \cdot \mathrm{Al}_{2} \mathrm{O}_{3}$ airborne-particle abrasion has been widely used on zirconia ${ }^{(10,11)}$.

The ceramic surfaces were airborne-particle abraded in the present study as a routine work. Airborne-particle abrasion with $\mathrm{Al}_{2} \mathrm{O}_{3}$ has been suggested as the preferred surface treatment method for high-strength ceramic materials such as alumina and zirconia ceramics ${ }^{(12,13)}$. Airborneparticle abrasion produces a roughening and forms irregularities on the substrate surface, which will promote the micromechanical interlocking of resin. This surface treatment may increase the surface area for bonding, surface energy and wettability ${ }^{(14,15)}$, thus allowing the polymer (resin composite) to flow into the surface ${ }^{(16)}$.

Different sizes of abrasive particles between 50 and $110 \mu \mathrm{m}$ are usually used ${ }^{(17)}$. In the present study, $50 \mu \mathrm{mAl}_{2} \mathrm{O}_{3}$ particles were used to provide micromechanical retention. The differences in particle size would bring about variations in superficial area size. Incidentally, the size of superficial area on a bonding surface directly influences bond strength. After airborne-particle abrasion it is important to remove loose particles not firmly attached to ceramics surface by ultrasonic cleaning before resin bonding ${ }^{(18,14)}$ because loose alumina particles might be left on the bonding surfaces which might affect long-term bond durability (particles might negatively influence both chemical adhesion and micromechanical interlocking) .

In present study ultrasonic cleaning was done by immersed the zirconia discs in distilled water for 5 minutes as Nishigawa ${ }^{(19)}$.However, the effect of ultrasonic cleaning after air abrasion is controversial, as Nishigawa ${ }^{(19)}$ showed that ultrasonic cleaning of zirconia ceramic in distilled water decreased the bond strength and Abd El Wahab ${ }^{(20)}$ concluded that different primers produce different bond strength between zirconia ceramic and resin cement and the air oil free cleaning method gave higher result than ultrasonic cleaning.

The results of the present study are coincident with those of Attia and Kern ${ }^{(21)}$ and Lehmann ${ }^{(22)}$ who demonstrated that ultrasonic cleaning methods had little effect on bonding to zirconia ceramic when a new universal primer (Monobond Plus) was used which contain phosphoric acid and sulfide methacrylate. In our study ultrasonic cleaning was effective on bond strength to zirconia ceramics when conventional primer (Monobond S) was used.

The bond between zirconia ceramics and resin cements can be established with application of primer which contain a silane coupling agent ${ }^{(23,24)}$. A conventional silane coupling agent which is ingredient in Monobond $\mathrm{S}$ primer contains approximately 1 to $2 \%$ of 3-methacryloxy propyl trimethoxysilane (MPS), which is prehydrolyzed and diluted in ethanol-water solution and then adjusted with acetic acid to a $\mathrm{pH}$ of 4 to 5 It has been used for the silanization of silica ceramics or silica coated zirconia ceramics for many years $(25,26)$. Silane-coupling agents are hybrid inorganicorganic bifunctional molecules and they play a recognized role by way of their use as adhesion promoting agents.

Typical silane-coupling agents contain an organofunctional part and three hydrolyzable alkoxy 
groups. Before becoming adhesion promoters, and in order to be activated, trialkoxysilanes must undergo a hydrolyzation reaction in a slightly acidic ethanol- water solvent to form silanols from trialkoxy groups. Silane molecules react with water to form three hydroxy-silyl groups $(-\mathrm{Si}-\mathrm{OH})$ from the corresponding methoxy-silyl groups $(-\mathrm{Si}-\mathrm{O}-$ CH3) ${ }^{(31)}$. The silanol groups then react further to form a siloxane (-Si-O-Si-O-) network with the silica deposited on the silica-based ceramics ${ }^{(24)}$.

The methacryloyl groups (monomeric end) of the silane molecules react with the methacryloyl groups of adhesive resins by means of a free radical polymerization process ${ }^{(24)}$. Conventional silanes are not as effective with high strength ceramics such as alumina and zirconia, as these ceramics are more chemically stable than silica containing glasses and ceramics and not as easily hydrolyzed ${ }^{(27)}$.

The universal primer (Monobond Plus) contains an alcohol solution of MPS, phosphoric acid methacrylate, and sulfide methacrylate. Therefore, it contains the same adhesive component (MPS) responsible for creating chemical bonding to silica ceramic or silica coated zirconia ceramic. Other components such as phosphoric acid methacrylate and sulfide methacrylate might be included to enhance chemical bonding to oxide ceramics and other prosthetic materials ${ }^{(21)}$. Airborne-particle abrasion plus the use of the new universal primer, which could create a chemical bond with the airabraded zirconia ceramic through phosphoric acid methacrylate and sulfide methacrylate groups, provided durable long-term resin bonding to zirconia ceramic.

In this study, Monobond Plus showed the statistically significant highest shear bond strength than Monobond S.These findings agree with Attia and Kern (21) and Lehmann (22).

Zirconia-based ceramics have a high strength and therefore restorations can be cemented with traditional cements or bonded with resin cements. If greater retention is required, bonded cementation with resin cements is recommended. Resin cements are composed of diacrylate resins and glass filler. They are usually dual-cured resins that can be lightactivated and can self-cure. In this study Variolink II cement was used, it is dual cure resin cement, it may also be applied in the light-curing technique only.

Variolink II is based on the advanced composite technology of Tetric ceram.The special filler composition of this technology gives it excellent physical properties, high abrasion resistance, excellent radiopacity, very good optical properties ,as well as continuous fluoride release.

The ISO TR 11450(ISO reports ) reported that 500 thermocycles (TC) in water $\left(5\right.$ and $\left.55^{\circ} \mathrm{C}\right)$,is an appropriate method to test thermal stability of a dental material .Moreover ,TC was used for acceleration the aging process as it is a way of artificial aging of the specimens ${ }^{(28)}$. TC could be used to study the long -term clinical bonding between resin cement and zirconia ceramics .In the present study specimens were thermocycled for 3.000 time in water $\left(5 \text { and } 55^{\circ} \mathrm{C}\right)^{(29)}$.

The result of the present study demonstrated that the use of Monobond Plus without ultrasonic cleaning to zirconia ceramics recorded the highest mean value $(27.60456 \pm 3.885427 \mathrm{MPa})$ followed by the use of Monobond Plus with ultrasonic cleaning $(22.0788 \pm 5.187271 \mathrm{MPa})$, then the use of Monobond $\mathrm{S}$ with ultrasonic cleaning $(13.38022 \pm 5.18527 \mathrm{MPa})$, while the use of Monobond S without ultrasonic cleaning recorded the lowest value $(7.604419 \pm 1.442523 \mathrm{MPa})$ (table 4).

The interpretation of different failure patterns is contradictory in the scientific literature. It was reported that, cohesive failure and mixed failure patterns are preferred to adhesive failure because they indicate low bond strength values (30,31). However,it was reported that mixed failures, which are predominantly within the composite resin restorative material, represent breaking stresses resulting from different mechanical properties of 
the bonding assembly, rather than from the real adhesive bond strength values ${ }^{(31,32)}$.

The initial high bond strength results was reflected on the failure pattern of debonded specimens as examined by SEM. In this study all groups showed cohesive ,mixed and adhesive failure table(5), in group IP the failure pattern was mainly cohesive within the adhesive luting resin that indicate highest SBS due to presence of phosphate acid methacrylate in universal primer (Monobond Plus ) figure (4), in group IS the failure pattern is mainly adhesive at adhesive luting resin/zirconia ceramic interface that indicate low SBS due to presence of loose alumina particles on zirconia surface and priming the surface by conventional primer (Monobond S ) figure (3), and in the other two groups the failure pattern is mixed, cohesive and adhesive figure(5).

Within limitation of this study we try to simulate natural condition but there is micro structural variation in tooth structure (enamel or dentin) that could result in interpretation of the result so, the cementation done by using Teflon mold to standardize the size of the applied cement area .The other limitation was the thermocycling step that done as a routine work.

\section{CONCLUSIONS}

1. The new universal primer (Monobond Plus) improved bonding to zirconia ceramic (MPS containing phosphoric acid and sulphide group) than conventional primer (Monobond S).

2. Ultrasonic cleaning method has positive effect on bond strength to zirconia ceramics when conventional primer was used but it had little or no positive effect when a new universal primer was used.

\section{REFERENCES}

1. Tan K, Pjetursson BE, Lang NP and Chan ES: A systemic review of the survival and complication rates of fixed partial dentures (FPDs) after an observation period of at least 5 years. Clin. Oral Implants Res., 2004; 15: 654-66.
2. Raigrodski AJ: Contemporary materials and technologies for all ceramic fixed partial dentures: a review of the literature. J Prosthet. Dent., 2004; 92: 557-62.

3. Jensen ME, Sheth JJ and Tolliver D: Etched porcelain resinbonded full veneer crowns: in vitro fracture resistance. Compendium 1989; 10: 336-8.

4. Borges GA, Spohr AM, Goes MF, Sobrinho LC and Chan DC: Effect of etching and airborne particle abrasion on themicrostructure of different dental ceramics. J Prosthet Dent, 2003; 89:479-88.

5. Kim BK, Bae HE, Shim JS and Lee KW: The influence of ceramic surface treatments on the tensile bond strength of composite resin to all-ceramic coping materials. J Prosthet Dent, 2005; 94:357-62.

6. Bottino MA, Valandro LF, Scotti R and Buso L. Effect of surface treatments on the resin bond to zirconium-based ceramic. Int J Prosthodont 2005; 18:60-5.

7. Amaral R, Ozcan M, Bottino MA and Valandro LF: Microtensile bond strength of a resin cement to glass infiltrated zirconia-reinforced ceramic.the effect of surface conditioning. Dent. Mater., 2006;22: 283-90.

8. Blatz MB, Chiche G, Holst S and Sadan A: Influence of surface treatment and simulated aging on bond strengths of luting agents to zirconia. Quintessence Int., 2007; 38: $745-53$

9. Quaas AC, Yang B and Kern M: Panavia F 2.0 bonding to contaminated zirconia ceramic after different cleaning procedures. Dent. Mater., 2007;23:506-12.

10. Blatz MB, Phark JH, Ozer F, Mante FK, Saleh N, Bergler $\mathrm{M}$ and Sadan A: In vitro comparative bond strength of contemporary self-adhesive resin cements to zirconium oxide ceramic with and without air-particle abrasion. Clin. Oral Investig., 2010;14(2):187-92.

11. Uo M, Sjogren G, Sundh A, Goto M, Watari F and Bergman M: Effect of surface condition of dental zirconia ceramic (Denzir) on bonding. Dent. Mater., 2006;25:626-31.

12. Wolfart M, Lehmann F, Wolfart S and Kern M: Durability of the resin bond strength to zirconia ceramic after using different surface conditioning methods. Dent. Mater., 2007;23:45-50.

13. Awliya W, Oden A, Yaman P, Dennison JB and Razzoog ME: Shear bond strength of a resin cement to densely sintered high-purity alumina with various surface conditions. Acta Odontol. Scand., 1998; 56:9-13. 
14. Wegner SM, Gerden W and Kern M: Effect of different artificial aging conditions on ceramic-composite bond strength. Int J Prosthodont., 2002; 15:267-72.

15. Lehmann F,Kern $M$ and Attiaa A : Influence of surface conditioning and cleaning methods on resin bonding to zirconia ceramic. J Dent. Mater., 2011;27:207-13.

16. Jennings CW: Surface roughness and bond strength of adhesives. J Adhes., 1972;4:25-38.

17. Phark JH, Duarte Jr S, Blatz M and Sadan A: An in vitro evaluation of the long-term resin bond to a new densely sintered high-purity zirconium-oxide ceramic surface. J Prosthet. Dent., 2009; 101:29-38.

18. Wolfort M, Lehmann F, Wolfort S and Kern M: Durabililty of resin bond strength to zirconia ceramic after using different surface conditioning methods. Dent. Mater., 2007;23:45-50.

19. Nishigawa G,Maruo $\mathrm{Y}$, Irie $\mathrm{M}$, Oka M, Yoshihara $\mathrm{K}$, Minagi S , Nagaoka N, Yoshida Y and Suzuki K: Ultrasonic cleaning of silica coated zirconia influences bond strength between zirconia and resin luting material . J Dent. Mater., 2008; $27: 842-8$

20. Abd El Wahab S: Influence of cleaning methods and primers on zirconia ceramic bonding using an adhesive composite resin .AL Azhar dental Assioation Journals, $2013 ; 3: 240-5$.

21. Attia A and Kern M: Long-term resin bonding to zirconia ceramic with a new universal primer. J Prosthet. Dent., 2011; 106:319-27.

22. Lehmann F,Kern M and Attiaa A : Influence of surface conditioning and cleaning methods on resin bonding to zirconia ceramic. J Dent. Mater., 2011;27:207-13.

23. Blatz MB, Sadan A and Kern M: Resin-ceramic bonding: a review of the literature. J Prosthet. Dent., 2003; 89:268-74.
24. Matinlinna JP, Lassila LV, Ozcan M, Yli-Urpo A and Vallittu PK: An introduction to silanes and their clinical applications in dentistry. Int. J Prosthodont., 2004;17:155-

25. Kern M: Resin bonding to oxide ceramics for dental restorations. J Adhes. Sci. Technol., 2009; 23: 1097-111.

26. Atsu SS, Kilicarslan MA, Kucukesmen HC, and Aka PS: Effect of zirconium-oxide ceramic surface treatments on the bond strength to adhesive resin. J Prosthet. Dent., 2006; 95:430-6.

27. Piascik JR, Swift EJ, Thompson JY, Grego S and Stoner BR: Surface modification for enhanced silanation of zirconia ceramics. Dent. Mater., 2009;25:1116-21.

28. Yahya NA, Lui JL, Chong K, Lim CM, Abu Kasim NH and Radzi Z: Effect of luting cement to push out bond strength of fiber reinforced post. Annal Dent.Univ. Malaya, 2008; 90:556-62.

29. Egilmez F, Ergum G, Cekic-Nagas I, Vallittu PK, Lassila $L V: I n f l u e n c e$ of cement thickness on the bond strength of tooth-colored post to root dentin after thermal cycling .Acta Odontologica Scandinavica,2012;71(1):175-82.

30. Oyague RC, Monticelli F, Toledano M, Osorio E, Ferrari $\mathrm{M}$ and Osorio R: Effect of water aging on microtensile bond strength of dual-cured resin cements to pre-treated sintered zirconium-oxide ceramics. Dent. Mater. 2009; 25:392-9.

31. Attia A and Kern M: Effect of cleaning methods after reduced-pressure air abrasion on bonding to zirconia ceramic. J Adhes. Dent., 2011;13: 561-7.

32. Scherrer SS, Cesar PF and Swain MV: Direct comparison of the bond strength results of the different test methods. A critical literature review. Dent. Mater., 2010;26:78-93. 